\title{
BMJ Open Systematic review and meta-analysis of the risk of rheumatoid arthritis- associated interstitial lung disease related to anti-cyclic citrullinated peptide (CCP) antibody
}

Hiroyuki Kamiya (1) , ${ }^{1}$ Ogee Mer Panlaqui ${ }^{2}$

To cite: Kamiya $\mathrm{H}$, Panlaqui 0M. Systematic review and meta-analysis of the risk of rheumatoid arthritis-associated interstitial lung disease related to anticyclic citrullinated peptide (CCP) antibody. BMJ Open 2021;11:e040465. doi:10.1136/ bmjopen-2020-040465

- Prepublication history and additional material for this paper are available online. To view these files, please visit the journal online (http://dx.doi. org/10.1136/bmjopen-2020040465).

Received 14 May 2020 Revised 11 January 2021 Accepted 23 January 2021

Check for updates

(c) Author(s) (or their employer(s)) 2021. Re-use permitted under CC BY-NC. No commercial re-use. See rights and permissions. Published by BMJ.

${ }^{1}$ Department of Respiratory Medicine, Tatebayashi Kosei Hospital, Tatebayashi, Gunma, Japan

${ }^{2}$ Department of Intensive Care Medicine, Northern Hospital, Epping, Victoria, Australia

Correspondence to Hiroyuki Kamiya; mlb04194@nifty.com

\section{ABSTRACT}

Objective To clarify the risk of rheumatoid arthritis-associated interstitial lung disease (RA-ILD) related to anti-cyclic citrullinated peptide (CCP) antibody.

Eligibility criteria Patients with RA with and without ILD were eligible. The primary outcome was the prevalence or incidence of ILD. Primary studies of any design aside from a case report were eligible.

Information sources Medline, EMBASE, Science Citation Index Expanded and Cochrane Central Register of Controlled Trials were searched from the inception through 12 November 2019.

Data extraction and risk of bias Two reviewers

independently selected eligible reports, extracted relevant data and assessed risk of bias using a modified Quality in Prognostic Studies tool.

Data synthesis Meta-analysis was conducted using a random-effects model.

Quality of evidence The Grades of Recommendation, Assessment, Development and Evaluation system was applied. Results Among 29 out of 827 records retrieved through electronic databases and four additional reports identified from other sources, 29 studies were focused for the review. A total of 10158 subjects were included and the mean age at inclusion was between 45.8 and 63.9 years. The mean RA duration was between 4.3 and 14.9 years. The positivity of anti-CCP antibody ranged from $50.7 \%$ to $95.8 \%$. All studies except for two were deemed as high risk of bias. A pooled analysis of univariate results demonstrated that the presence of anti-CCP antibody was significantly associated with RA-ILD with an OR of 2.10 (95\% Cl: 1.59 to 2.78). Similarly, the titre of anti-CCP antibody was significantly higher for RA-ILD with a standardised mean difference of 0.42 ( $95 \% \mathrm{Cl} 0.20$ to 0.65$)$. These results were confirmed by multivariate analysis in the majority of studies and consistent by any subgroup and sensitivity analyses. Conclusion The presence and higher titres of anti-CCP antibody were suggested to be significantly associated with an increased risk of RA-ILD. However, the quality of evidence was rated as low or very low.

\section{BACKGROUND}

Rheumatoid arthritis (RA) is a systemic autoimmune disorder that is characterised by a chronic synovial inflammation and eventual
Strengths and limitations of this study

- This systematic review and meta-analysis addressed the risk of rheumatoid arthritis-associated interstitial lung disease (RA-ILD) related to both the presence and titres of anti-cyclic citrullinated peptide (CCP) antibody, which was not clarified in previous literature.

- A substantial variance in the results of primary studies, which may have been derived from the diversity of anti-CCP antibody assays and included subjects, may undermine the generalisability of the findings of this study.

- The usefulness of the findings may be limited in clinical practice because of high probability of the autoantibody positivity for RA without ILD and no standard cut-off points for its assays.

joint destruction. ${ }^{1}$ Although arthritis is the main manifestation of the disease, it also damages diverse extra-articular organs such as heart, lung, kidney, eye and skin. ${ }^{2}$ Interstitial lung disease (ILD) is one of the most common comorbidities of RA and the prevalence of ILD for patients with RA is reported to be $10 \%-40 \%$ although it varies depending on the target population, a definition of the disease and diagnostic modalities. ${ }^{3}$ A complication of ILD deeply affects the prognosis of RA because RA-associated ILD (RA-ILD) is often progressive and only a limited therapeutic option is available. ${ }^{4}$ It is also complicated by acute exacerbation and lung cancer. ${ }^{56}$ As a result, ILD is reported to be the third leading cause of deaths of $\mathrm{RA}^{7}$ and approximately two-thirds of patients with RA-ILD eventually die within 5 years, resulting in a hazard ratio (HR) of mortality about 3.0 in comparison to RA without ILD. ${ }^{8}$ Moreover, the most common type of ILDs among RA-ILDs, that is, usual interstitial 
pneumonia (UIP), ${ }^{9}$ demonstrates the worst prognosis, which is similar to the mortality of idiopathic pulmonary fibrosis (IPF). ${ }^{10}$ In this context estimating the risk of developing ILD will help clinicians' decision-making and may improve the prognosis of the disease. ${ }^{11}$ Historically, a number of studies investigated risk factors for the development of ILD and some clinical information are reported to be associated with an increased risk of RA-ILD, which include male gender ${ }^{12}$ smoking, ${ }^{13}$ severe disease $^{14}$ and rheumatoid factor (RF). ${ }^{15}$ Anticitrullinated peptide antibody (ACPA) is a specific marker for RA and included in the latest classification criteria for an accurate diagnosis of the disease ${ }^{16}$ Currently, anti-cyclic citrullinated peptide (CCP) antibody, representing ACPAs, is available commercially and usually measured in clinical practice. The autoantibody is also reported to be associated with an increased risk of extra-articular manifestations such as ILD. ${ }^{17}$ However, previous studies noted inconsistent results ${ }^{18} 19$ and the former systematic review seems to be limited by relatively a small number of studies and unclear definition of ILD and IPF. ${ }^{20}$ The aim of this systematic review and meta-analysis was to clarify current evidence regarding the association of anti-CCP antibody with RA-ILD.

\section{METHODS}

This review was conducted and reported according to the Preferred Reporting Items for Systematic Reviews and Meta-Analyses ${ }^{21}$ and the Meta-analysis of Observational Studies in Epidemiology statement. ${ }^{22}$

\section{Patient and public involvement}

There was no patient and public involvement in the whole process of conducting this research.

\section{Eligibility}

Patients with RA were eligible for this review. RA was diagnosed based on its widely used classification criteria, that is, the 1987 American College of Rheumatology classification criteria ${ }^{23}$ and the 2010 American College of Rheumatology/European League Against Rheumatism classification criteria. ${ }^{16}$ ILD was characterised by interstitial inflammatory and fibrotic changes in pulmonary parenchyma and diagnosed based on symptomatic, functional, radiological and/or pathological findings. ${ }^{24}$ The pattern of ILD was classified following the international multidisciplinary classification such as an official American Thoracic Society/European Respiratory Society statement. ${ }^{25}$ Other pulmonary lesions associated with RA such as bronchiolitis, bronchiectasis and pleuritis were all excluded. An overlap with other connective tissue diseases was included if RA was the main disease of interest in the study. There was no limitation regarding demographic features of subjects, such as gender and ethnicity, duration of RA and ILD and the severity of the disease unless they were less than the age of 18 . Subjects were allowed to participate at any point in time along their clinical course of the disease.

Anti-CCP antibody was examined using Enzyme-Linked Immunosorbent Assay (ELISA). ${ }^{26}$ Although measurements of anti-CCP antibody were different among manufacturers and each institution adopted a different test, all kinds of anti-CCP antibody assays were eligible for the review. However, ACPA, which was not specified as anti-CCP antibody, was excluded because it may have represented autoantibodies against different citrullinated peptides.

The outcome of interest in this review was the prevalence or incidence of ILD. Any design of primary studies other than a case report was eligible if it described the association of anti-CCP antibody with RA-ILD. Conference proceedings, letters or editorials and review articles were ineligible. Only reports published in English was considered.

\section{Search strategy}

The following electronic databases were searched, Medline, EMBASE, Science Citation Index Expanded and Cochrane Central Register of Controlled Trials, using subject headings and text words related to study population such as 'rheumatoid arthritis', 'interstitial lung disease' and 'anti-cyclic citrullinated peptide antibodies' (e-Appendix). Search terms were constructed referring to a systematic review in a similar research area identified through the Cochrane Database of Systematic Reviews. ${ }^{27}$ Methodology filters were not used to avoid limiting the sensitivity of the search. The search was covered from the inception of each database through to 12 November 2019. The reference lists of eligible studies and relevant review articles were also hand-searched to identify additional reports. Google Scholar was employed to search grey literature. ${ }^{28}$

\section{Study selection and data collection process}

Two reviewers (HK and OMP) independently examined titles and abstracts of all retrieved articles to select eligible reports. The same reviewers also extracted relevant data based on a modified data extraction form, which was previously published in a protocol paper for a systematic review. ${ }^{29}$ Any uncertainty or disagreement between reviewers arising from these processes was resolved through discussion. The following data were extracted from each eligible study: first author's name, year of publication, study location, study design, sample size and its demographic features, ILD patterns if available, manufacturers of anti-CCP antibody tests and their cut-off points if available, a proportion of positivity and titres of anti-CCP antibodies for RA with and without ILD, methods for statistical analysis, summary statistics and items associated with a risk of bias.

\section{Risk of bias in individual studies}

As all studies investigated the association of anti-CCP antibody with RA-ILD as risk prediction, the Quality in 
Prognostic Studies (QUIPS) tool was modified and applied to assess a risk of bias in individual studies. ${ }^{30}$ However, one of the six domains that constitute the tool, that is, 'the attrition of study population', was considered irrelevant and thus excluded because all studies were designed as cross-sectional or case-control studies. Each domain received an individual bias rating (low, moderate or high), with an overall risk of bias based on a total rating of all domains. For example, a study showing a low risk of bias across all domains was deemed as being subject to a low risk of bias overall.

\section{STATISTICAL ANALYSIS}

\section{Summary statistics}

The risk of RA-ILD associated with the presence of anti-CCP antibody was measured using either risk ratios (RRs) or odds ratios (ORs). In a case where titres of anti-CCP antibody were compared between the two comparative groups with or without ILD, the mean difference (MD) was calculated to reveal the difference of the autoantibody titres. If the median was utilised instead of the mean, it was presented for each of the two groups. If the summary statistics were not provided directly, the ORs or RRs were calculated manually based on the absolute number of the outcome across the two comparative groups.

\section{Data synthesis}

The effect of an association between anti-CCP antibody and RA-ILD was statistically combined if it was presented using the same statistics in three or more studies. The results were summarised using ORs if anti-CCP antibody was reported as binary (positive/negative). If the titre of anti-CCP antibody was reported, a standardised MD (SMD) (calculated as Hedge's g) was utilised to combine the results. ${ }^{31}$ If the median, range or interquartile range (IQR) was described to report the autoantibody titres, they were converted to the mean and standard deviation (SD), using a formula reported by a previous study, to be summarised as SMDs. ${ }^{32}$ Only the results of univariate analysis were combined, whereas those of multivariate analysis were described qualitatively because adjusted variables in multivariate models varied substantially between studies and pooling these data could be misleading. If metaanalysis was feasible from the collated data, it was conducted using a random-effects model employing the DerSimonian and Laird method. ${ }^{33}$ Meta-analysis was conducted using the statistical software package, Review Manager (RevMan) V.5.3 (Copenhagen: The Nordic Cochrane Centre, The Cochrane Collaboration, 2014). Statistical significance was considered with a p-value of $<0.05$. If combining data were deemed inappropriate due to a small number of studies, the results were reported qualitatively.

\section{Heterogeneity between studies}

Between-study variance was assessed using both $Q$ statistics and $\mathrm{I}^{2}$ value. For the assessment of heterogeneity between studies, statistical significance was considered with a p-value of $<0.1$ due to the low power of the test. Magnitude of heterogeneity was categorised as low $(<30 \%)$, moderate $(\geq 30 \%,<50 \%)$, considerable $(\geq 50 \%,<70 \%)$ and substantial $(\geq 70 \%) .{ }^{34}$ When heterogeneity was identified, the $95 \%$ prediction interval (PI) was presented in addition to the 95\% confidence interval (CI) ${ }^{35}$ To better interpret sources of heterogeneity, subgroup analysis was conducted based on study location (Asia or non-Asia) and study design (crosssectional or case-control). Sensitivity analysis was also considered focusing on the measurements of anti-CCP antibody (same manufacturer and same generation of the autoantibody assay). A meta-regression analysis was also conducted to assess the effect of other potential confounders, that is, age, gender, smoking history, RA duration, diagnostic criteria for RA and ILD and a proportion of positivity of anti-CCP antibody. The analysis was conducted using SAS ODA (SAS Institute, Cary, NC, USA).

\section{Meta-biases}

Small study bias (such as publication bias) was examined graphically using a funnel plot and statistically by the Egger's test using Stata V.14 (STATA Corp LLC., College Station, TX, USA) if 10 or more studies were available for meta-analysis. ${ }^{36}$ Statistical significance of the test was considered with a p-value of $<0.1$ due to the low power of the test.

\section{Confidence in cumulative evidence}

The Grades of Recommendation, Assessment, Development and Evaluation (GRADE) for prognosis ${ }^{37}$ was applied to assess the credibility of evidence generated from this review because all studies investigated the association of anti-CCP antibody with RA-ILD as risk prediction.

\section{RESULTS}

\section{Search for eligible studies}

Out of a total of 827 records identified through a search of five electronic databases, 182 duplicates were removed and 645 records were screened by titles and abstracts. After 320 records consisting of non-English reports $(n=16)$ and 304 articles of ineligible types (conference proceedings $(n=153)$, case reports $(n=72)$, editorials or letters $(n=10)$ and review articles $(\mathrm{n}=69)$ ) and 265 irrelevant papers were further excluded, the remaining 60 records were retrieved as fulltexts. Out of these, 29 reposts/studies were eligible for the review and additionally four reports were identified through a hand-search of references of eligible studies. As a result, a total of 33 reports were considered for the review (figure 1). In each of three different groups, which conducted two studies sharing the same cohort, only the study with a larger sample size was included for the review. ${ }^{38-40}$ Similarly, among three studies conducted by one group, the study with the largest sample size was included for the review. ${ }^{41}$ Furthermore, another study among these three studies was also included because it reported two different cohorts, one of which was not overlapped by the other studies. ${ }^{42}$ There was also a study that reported two different cohorts, only one of which was included because it was not overlapped by the other studies. ${ }^{43}$ Finally, a total of 29 studies/cohorts were focused for further analysis. ${ }^{38-66}$ 


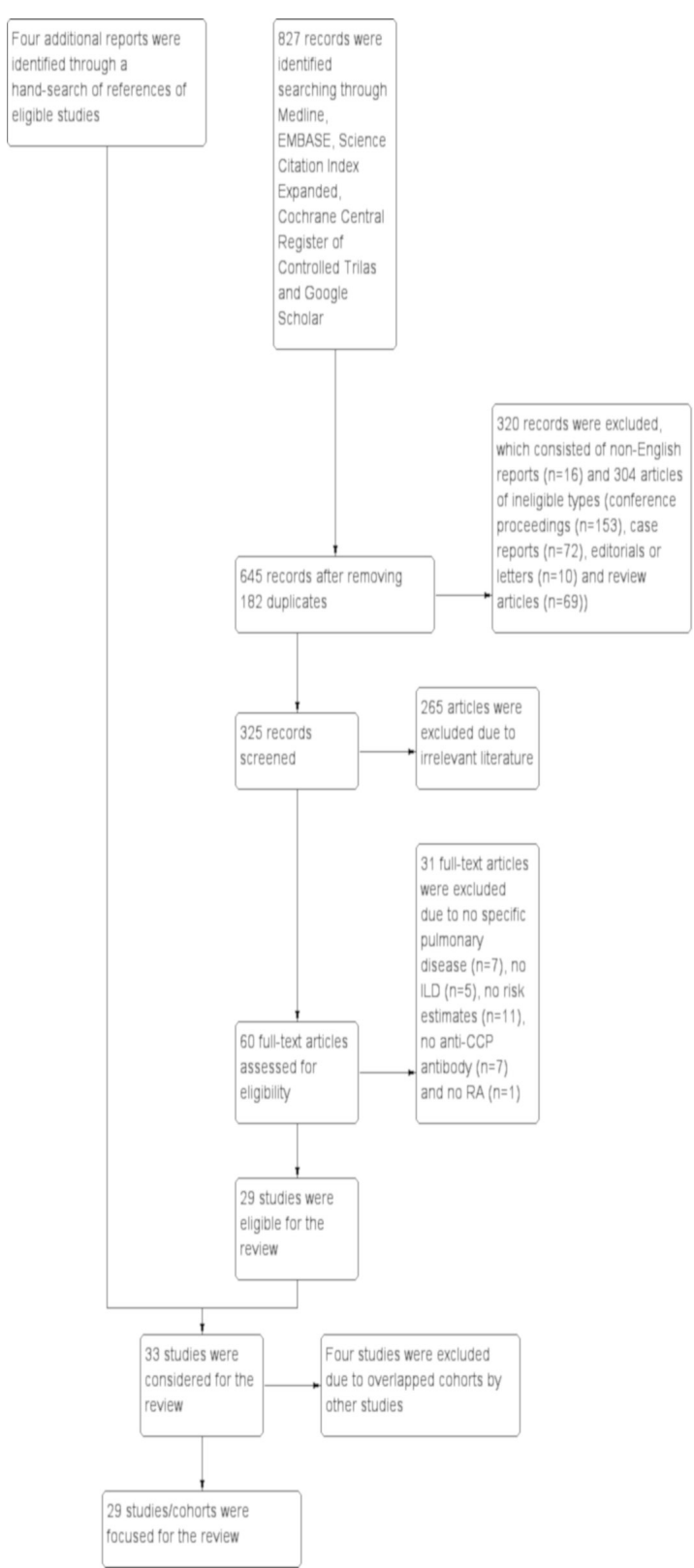

Figure 1 Study flow diagram. Out of a total of 827 records identified searching through five electronic databases, that is, Medline, EMBASE, Science Citation Index Expanded, Cochrane Central Register of Controlled Trials and Google Scholar, 645 records were screened by titles and abstracts after removing 182 duplicates. After excluding 320 records consisting of non-English reports $(n=16)$ and articles of ineligible types $(n=304)$ (conference proceedings $(n=153)$, case reports $(n=72)$, editorials or letters $(n=10)$ and review articles $(n=69)$ ) and 265 irrelevant reports, 60 records were retrieved as full-texts. Out of these, 31 records were excluded due to no specific pulmonary disease $(n=7)$, no ILD $(n=5)$, no risk estimates $(n=11)$, no anti-CCP antibody $(n=7)$ and no RA $(n=1)$. The remaining 29 reposts/studies were eligible for the review and additionally four reports were identified through a hand-search of references of eligible studies. As a result, a total of 33 reports/studies were considered for the review. Among them, four studies were excluded due to overlapped cohorts by other studies and finally a total of 29 studies/cohorts were focused for further analysis. CCP, cyclic citrullinated peptide; ILD, interstitial lung disease.
Characteristics of included studies

Study location of a total of 29 studies was distributed globally with Asia in the largest number $(\mathrm{n}=15)$, which was followed by the Americas $(n=7)$, Europe $(n=3)$, Africa $(n=2)$ and others $(n=2)$. Twenty-two studies were crosssectional while the remaining seven were case-control studies. A complication of other CTDs was mentioned in 10 studies and ILD patterns were detailed in three studies. The number of subjects enrolled in each study ranged from 41 to 2702, which amounted to 10158 subjects in total and the mean age at inclusion was between 45.8 and 63.9 years. The proportion of men, smoking history and ILD ranged from $4.0 \%$ to $90.1 \%, 1.9 \%$ to $98.9 \%$ and $4.9 \%$ to $71.6 \%$, respectively. The mean duration of RA was between 4.3 and 14.9 years and the disease activity, which was represented by the disease activity score 28 , was between 2.5 and 5.4 as a mean value (table 1 ). Other baseline characteristics of included studies were depicted in the supplementary file (online supplemental e-Table 1). The generation of anti-CCP antibody tests was specified in 14 studies, which consisted of the second generation in 12 studies and the third generation in 2 studies. The proportion of positivity of anti-CCP antibody was reported in 21 studies, which ranged from $50.7 \%$ to $95.8 \%$, while the titre of the autoantibody was described in 18 studies (table 2).

\section{Risk of bias in individual studies}

All studies except for two contained high risk of bias rating in at least one domain and thus was deemed as high risk of bias. Among the five domains constituting the QUIPS tool, the risk of bias for statistical analysis and reporting and ILD confirmation were rated as high in the majority of studies due to no or insufficient information regarding model building process and inconsistent diagnostic procedures. The remaining two studies were rated as moderate risk of bias (table 3 ).

\section{ASSOCIATION OF ANTI-CCP ANTIBODY WITH RA-ILD Univariate result}

The association of positivity of anti-CCP antibody with RA-ILD was reported in 20 studies. Eight out of these studies demonstrated significant results with the ORs ranging from 1.98 to 44.5 (table 2). Excluding one study, ${ }^{47}$ which conducted a stratified analysis based on the level of the autoantibody titre and thus was not combined, a meta-analysis of 19 out of these 20 studies demonstrated that the presence of anti-CCP antibody was significantly associated with RA-ILD with an OR of 2.10 (95\% CI: 1.59 to 2.78 ) with moderate heterogeneity $\left(\chi^{2}=29.7, p=0.04, I^{2}=39 \%\right)$ (figure 2$)$.

The titre of anti-CCP antibody was compared between RA with and without ILD in 18 studies. Two studies employed the same assay (INOVA Diagnostics) to examine the titre of anti-CCP antibody and reported higher titres associated with RA-ILD with an MD of 79.5 (95\% CI: 9.72 to 149.3$)^{46}$ and a median value of 220 for RA-ILD versus 120 for RA without $\mathrm{ILD}^{48}{ }^{48}$ respectively. Other two studies examined the titre of 

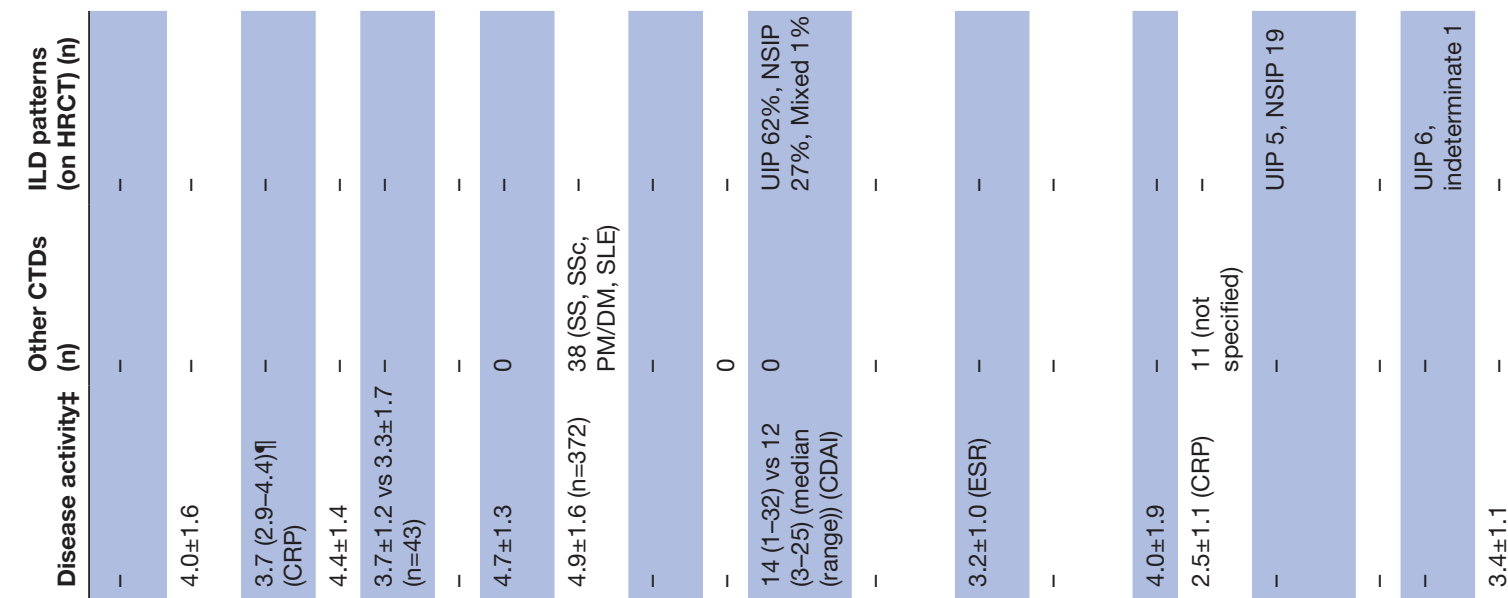

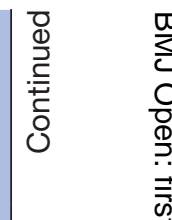

$\stackrel{\vec{F}}{\stackrel{9}{+}}$

흘

$\frac{\nabla}{2}$
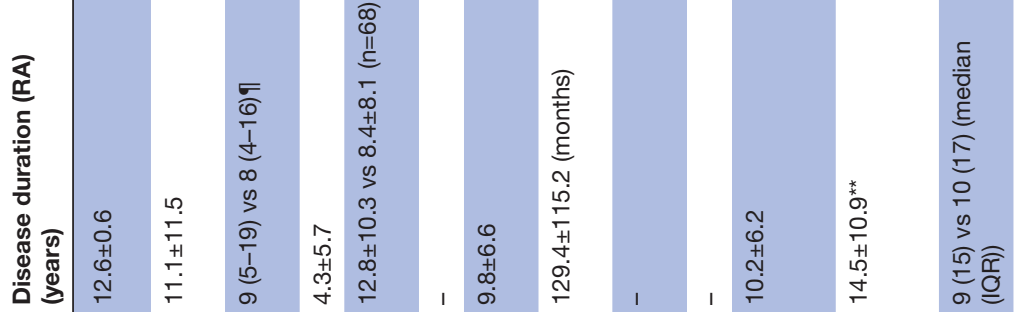

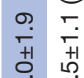

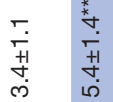

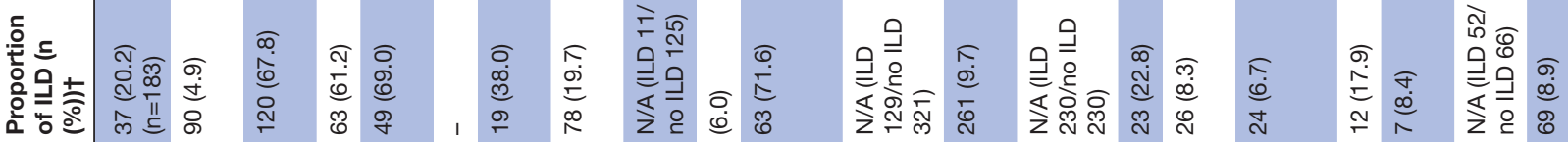

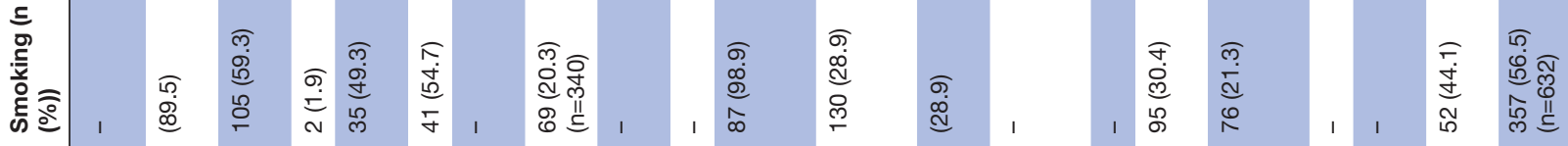

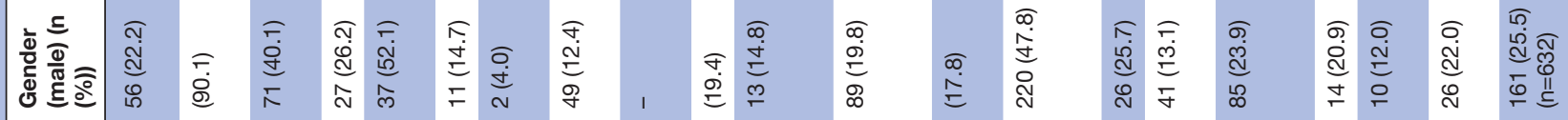

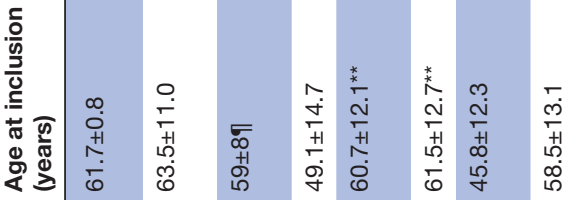
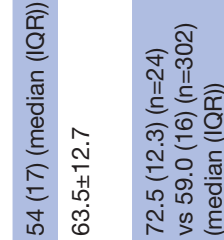

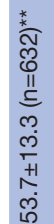
है

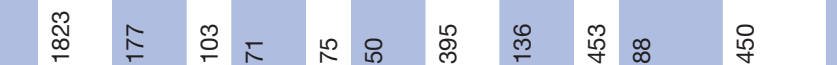

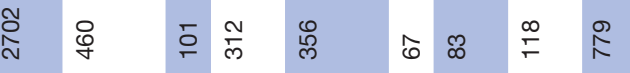

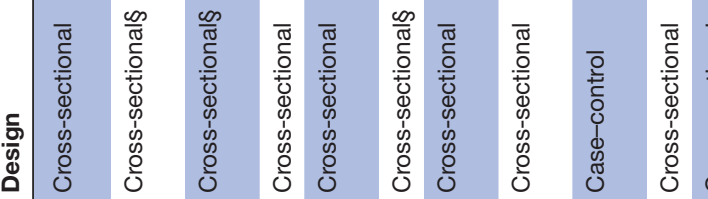

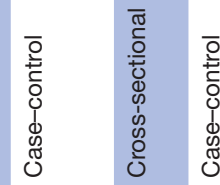

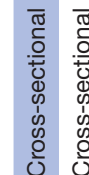

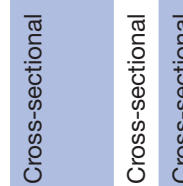

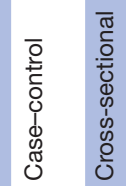
:

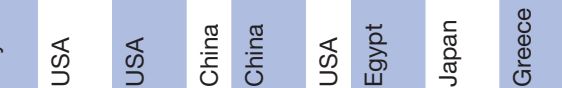

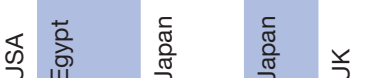
䒓

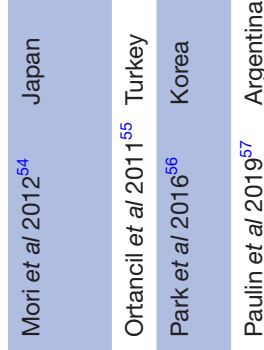




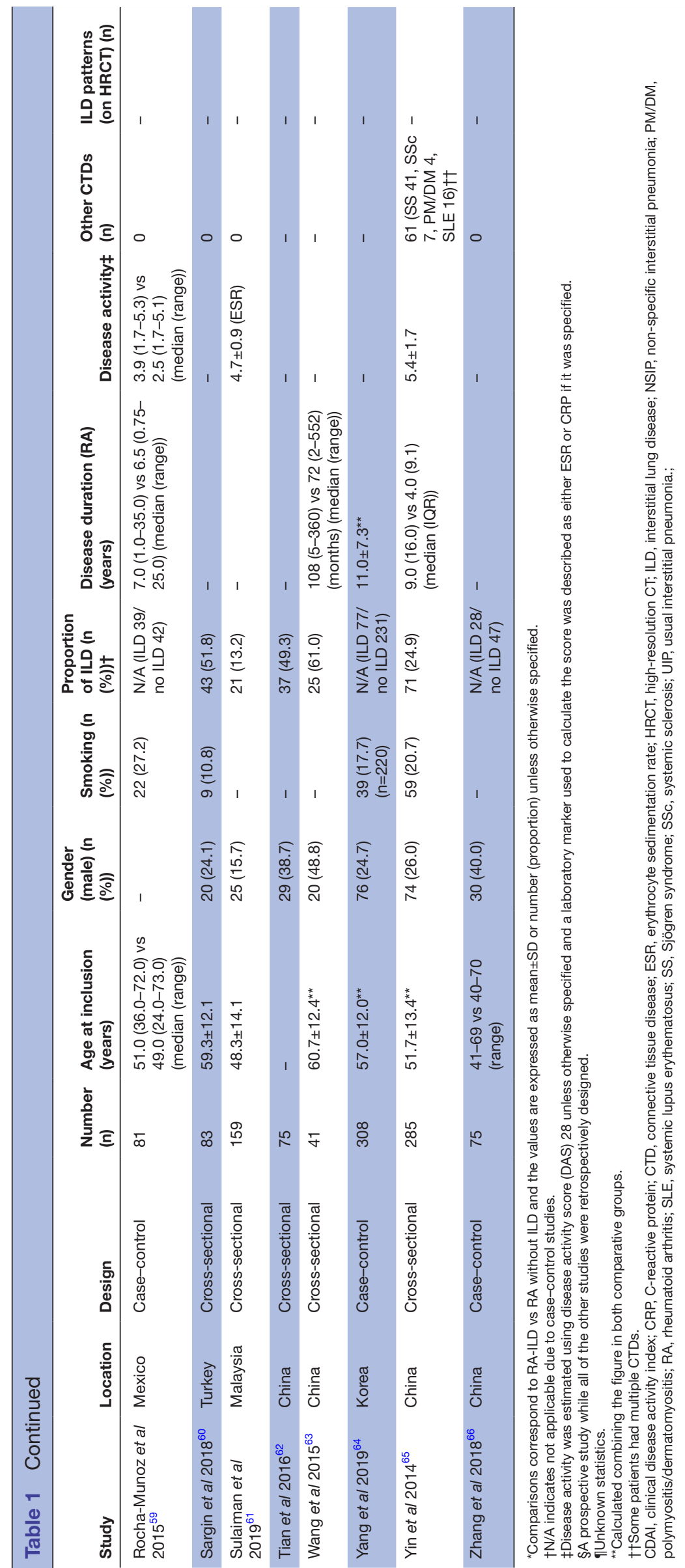




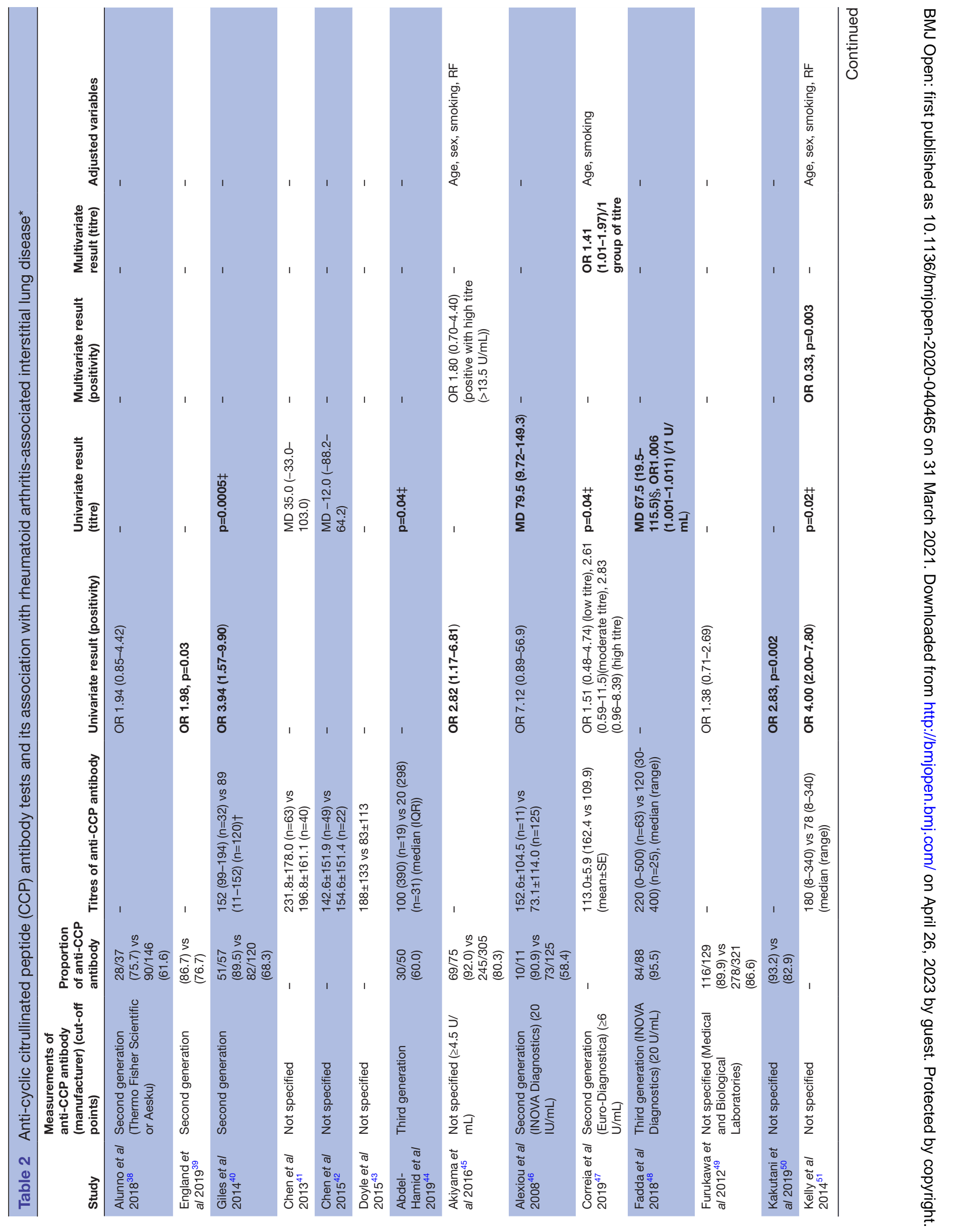




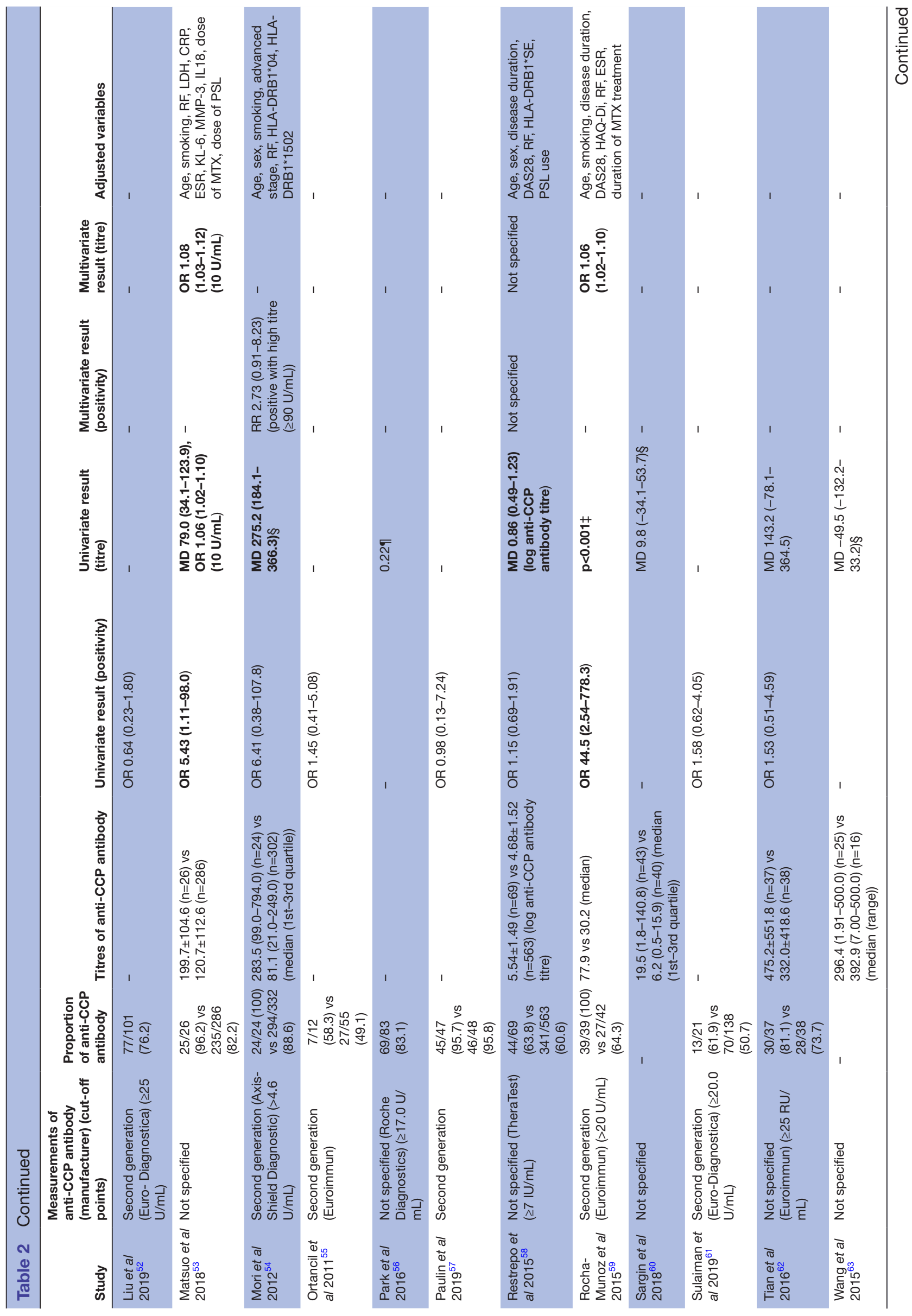




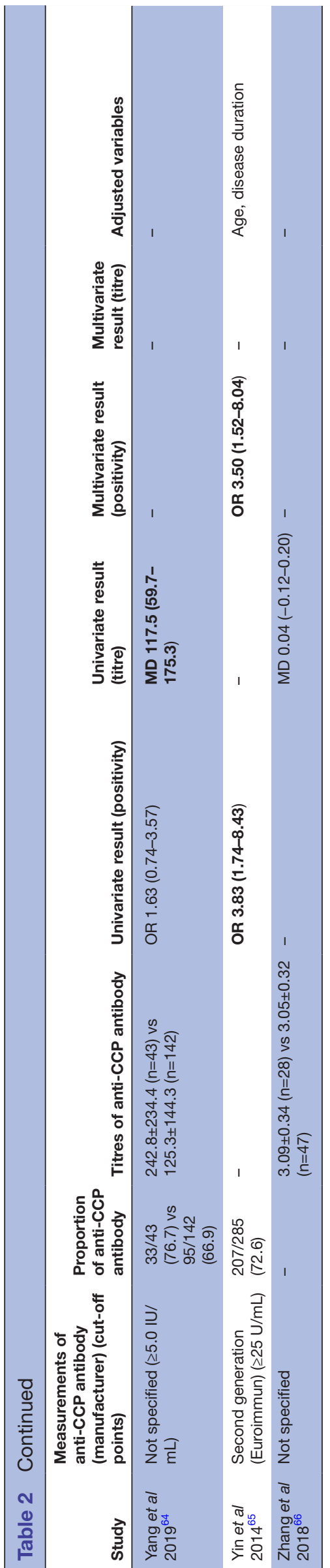

the autoantibody using another assay (Euroimmun). One of them demonstrated higher titres associated with RA-ILD with a median value of 77.9 for RA-ILD versus 30.2 for RA without $\mathrm{ILD}^{59}$ and the other study reported non-significant result with an MD of 143.2 (95\% CI: -78.1 to 364.5$){ }^{62}$ All of the other studies utilised a different or unknown measurement to examine the titre of the autoantibody. Overall, 11 studies demonstrated significant results with higher titres associated with RA-ILD (table 2). Excluding six studies ${ }^{40447515659}$ where MDs were unable to be calculated, a meta-analysis of 12 out of these 18 studies demonstrated that the titre of anti-CCP antibody was significantly higher for RA-ILD with an SMD of 0.42 (95\% CI: 0.20 to 0.65 ) with considerable heterogeneity $\left(\chi^{2}=36.0, \mathrm{p}=0.0002, \mathrm{I}^{2}=69 \%\right)$ (figure 3 ).

\section{Multivariate result}

Multivariate analysis was conducted in eight studies where detailed results were available in seven studies and adjusted variables were diverse between studies. Six of these seven studies demonstrated a positive association between the presence or higher titres of anti-CCP antibody and RA-ILD and the results were statistically significant in four studies (table 2). One study ${ }^{65}$ revealed the association of positivity of anti-CCP antibody with RA-ILD as an OR of 3.50 (95\% CI: 1.52 to 8.04) (table 2). The association of the titre of anti-CCP antibody with RA-ILD was reported by three studies as ORs of 1.41 (95\% CI: 1.01 to 1.97), 1.08 (95\% CI: 1.03 to $1.12)$ and 1.06 (95\% CI: 1.02 to 1.10$).{ }^{475359}$

\section{Subgroup analysis}

Subgroup analysis was conducted based on both study location and study design. There was no significant difference in the effect size of the positivity of anti-CCP antibody with ORs of 2.02 (95\% CI: 1.37 to 2.99) by Asian reports and 2.22 (95\% CI: 1.45 to 3.39$)$ by non-Asian reports $(\mathrm{p}=0.75)$ (online supplemental e-Figure 1). Similarly, there was no significant difference in the effect size of the titre of anti-CCP antibody with SMDs of 0.38 (95\% CI: 0.04 to 0.71 ) by Asian reports and 0.49 (95\% CI: 0.24 to 0.74$)$ by non-Asian reports $(\mathrm{p}=0.58)$ (online supplemental e-Figure 2). There was no significant difference in the effect size of the positivity of anti-CCP antibody with ORs of 2.00 (95\% CI: 1.48 to 2.71) by cross-sectional studies and 2.53 (95\% CI: 1.26 to 5.08 ) by case-control studies $(\mathrm{p}=0.55)$ (online supplemental e-Figure 3). Similarly, there was no significant difference in the effect size of the titre of anti-CCP antibody with SMDs of $0.39(95 \%$ CI: 0.11 to 0.67$)$ by cross-sectional studies and $0.50(95 \%$ CI: 0.12 to 0.89$)$ by case-control studies $(\mathrm{p}=0.65)$ (online supplemental e-Figure 4).

\section{Sensitivity analysis}

Sensitivity analysis was conducted focusing on the measurements of anti-CCP antibody. A pooled analysis of 10 studies that examined the second generation of anti-CCP antibody test demonstrated that the presence of anti-CCP antibody was significantly associated with RA-ILD with an OR of 2.22 (95\% CI: 1.42 to 3.45) (online supplemental e-Figure 5). A pooled analysis of three studies that examined the second 
Table 3 Risk of bias in individual studies

\begin{tabular}{|c|c|c|c|c|c|}
\hline Study & Study participation & $\begin{array}{l}\text { Anti-CCP antibody } \\
\text { measurement }\end{array}$ & ILD confirmation & Study confounding & $\begin{array}{l}\text { Statistical analysis } \\
\text { and reporting }\end{array}$ \\
\hline Alunno et al $2018^{38}$ & Moderate risk & Low risk & High risk & High risk & High risk \\
\hline England et al $2019^{39}$ & Moderate risk & High risk & High risk & Low risk & High risk \\
\hline Giles et al $2014^{40}$ & Moderate risk & Low risk & High risk & Moderate risk & High risk \\
\hline Chen et al $2013^{41}$ & Low risk & High risk & Low risk & Moderate risk & High risk \\
\hline Chen et al $2015^{42}$ & Moderate risk & Low risk & Low risk & Moderate risk & High risk \\
\hline Abdel-Hamid et al $2019^{44}$ & Moderate risk & Moderate risk & High risk & Moderate risk & High risk \\
\hline Akiyama et al $2016^{45}$ & Low risk & Moderate risk & High risk & Moderate risk & Moderate risk \\
\hline Alexiou et al $2008^{46}$ & Moderate risk & Low risk & High risk & High risk & High risk \\
\hline Correia et al $2019^{47}$ & Moderate risk & Low risk & Low risk & Moderate risk & High risk \\
\hline Fadda et $a / 2018^{48}$ & Moderate risk & Low risk & Low risk & Moderate risk & High risk \\
\hline Liu et al $2019^{52}$ & Moderate risk & Low risk & High risk & Moderate risk & High risk \\
\hline Matsuo et al $2018^{53}$ & Low risk & Moderate risk & High risk & Moderate risk & Moderate risk \\
\hline Mori et al $2012^{54}$ & Low risk & Low risk & Low risk & Moderate risk & Moderate risk \\
\hline Ortancil et al $2011^{55}$ & Moderate risk & Low risk & High risk & Moderate risk & High risk \\
\hline Park et al $2016^{56}$ & Low risk & Low risk & Low risk & High risk & High risk \\
\hline Paulin et al $2019^{57}$ & Moderate risk & High risk & High risk & Moderate risk & High risk \\
\hline Restrepo et al $2015^{58}$ & Moderate risk & Low risk & High risk & Moderate risk & Moderate risk \\
\hline Rocha-Munoz et al $2015^{59}$ & Moderate risk & Low risk & High risk & Moderate risk & Low risk \\
\hline Sargin et al $2018^{60}$ & Moderate risk & High risk & High risk & Moderate risk & High risk \\
\hline Sulaiman et al $2019^{61}$ & Moderate risk & Low risk & High risk & High risk & High risk \\
\hline
\end{tabular}

Text in bold indicates high risk of bias.

CCP, cyclic citrullinated peptite; ILD, interstitial lung disease.;

generation of anti-CCP antibody test by the same manufacture (Euroimmun, Lübeck, Germany) demonstrated that the presence of anti-CCP antibody was significantly associated with RA-ILD with an OR of 3.81 (95\% CI: 1.08 to 13.5$)$ (online supplemental e-Figure 6).

Sensitivity analysis was also conducted for the titre of anti-CCP antibody focusing on the same summary statistics. A pooled analysis of seven studies where MDs were available without a conversion of summary statistics demonstrated higher titres associated with RA-ILD with an MD of 52.5 (95\% CI: 5.76 to 99.2) (online supplemental e-Figure 7).

All of these sensitivity analyses generated no significant difference of the results.

\section{Meta-regression analysis}

The effect of the presence of anti-CCP antibody on RA-ILD was not influenced by any other potential confounders. Similarly, the association of the titre of anti-CCP antibody with RA-ILD was not affected by any of them although gender and RA duration were significant in univariate analysis (online supplemental e-Table 2).

\section{Additional analysis}

Two funnel plots (for both positivity and titre of anti-CCP antibody) were constructed to investigate small study bias, both of which demonstrated no apparent asymmetry (online supplemental e-Figure 8 and 9 , respectively). This graphical assessment was confirmed statistically by the Egger's test, which demonstrated no statistical significance $(p=0.15$ and 0.28 , respectively).

\section{Assessment of evidence level}

Study limitation was considered present in all of the evidence because no studies were deemed as low risk of bias. Publication bias was also considered present in all of the evidence due to the property of studies of risk prediction ${ }^{37}$ although it was not confirmed in both graphical and statistical analyses 
Odds Ratio

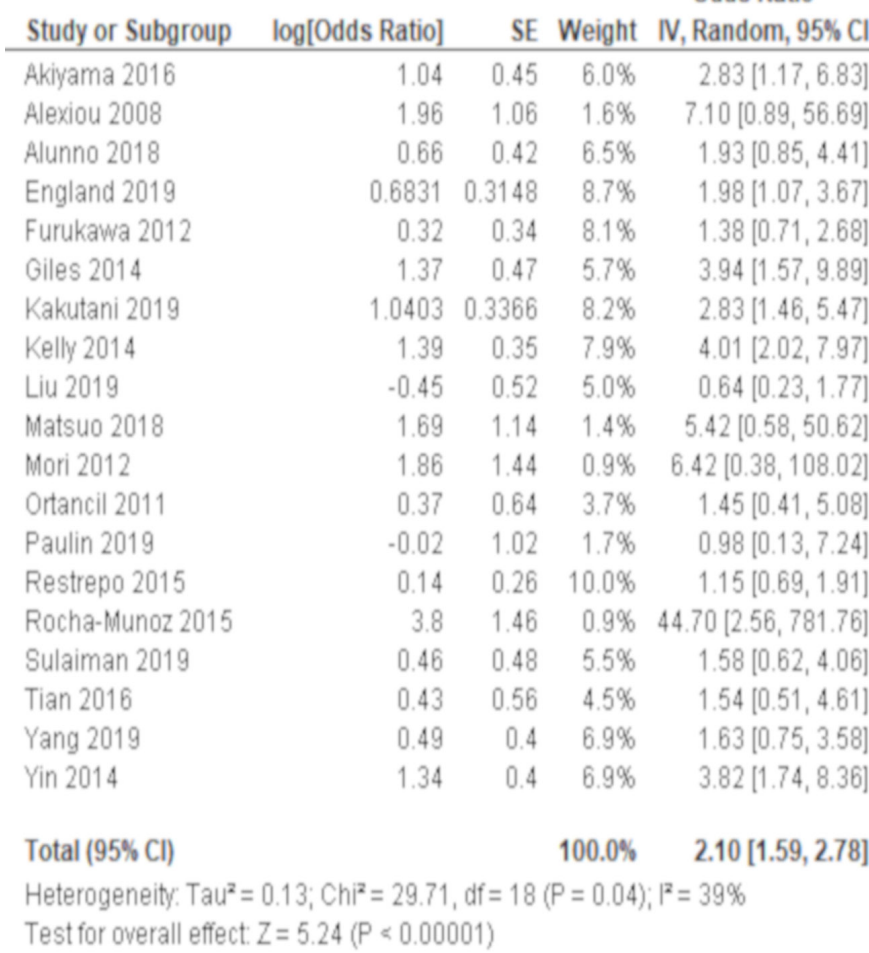

Odds Ratio IV, Random, $95 \% \mathrm{Cl}$

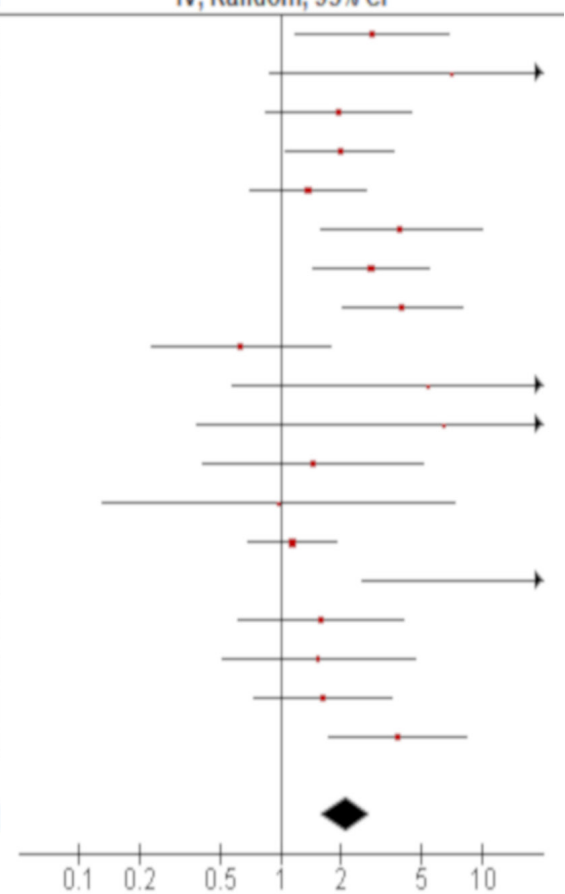

Figure 2 Forrest plot of the result of univariate analysis regarding the association of positivity of anti-cyclic citrullinated peptide (CCP) antibody with rheumatoid arthritis-associated interstitial lung disease (RA-ILD) The results of univariate analyses in 19 studies were pooled for meta-analysis. The positivity of anti-CCP antibody was significantly associated with RA-ILD with an OR of 2.10 (95\% Cl: 1.59 to $2.78, p<0.00001 / 95 \%$ prediction interval: 0.93 to 4.76$)$. There was moderate heterogeneity $\left(\chi^{2}=29.7\right.$, $\left.\mathrm{p}=0.04, \mathrm{I}^{2}=39 \%\right)$.

regarding univariate results. Overall, the level of evidence derived from this review was rated as low or very low (table 4).

\section{DISCUSSION}

This study demonstrated using a pooled analysis of univariate results that the presence of anti-CCP antibody was significantly associated with RA-ILD and the titre of anti-CCP antibody was significantly higher for RA-ILD than RA without ILD. The results were confirmed by multivariate analyses in the majority of studies that reported it. These findings suggest that anti-CCP antibody is related to an increased risk of ILD for patients with RA. As this review was based on a large number of studies conducted globally and the results were reproduced by any subgroup and sensitivity analyses, these findings will be generalisable to a broader population.

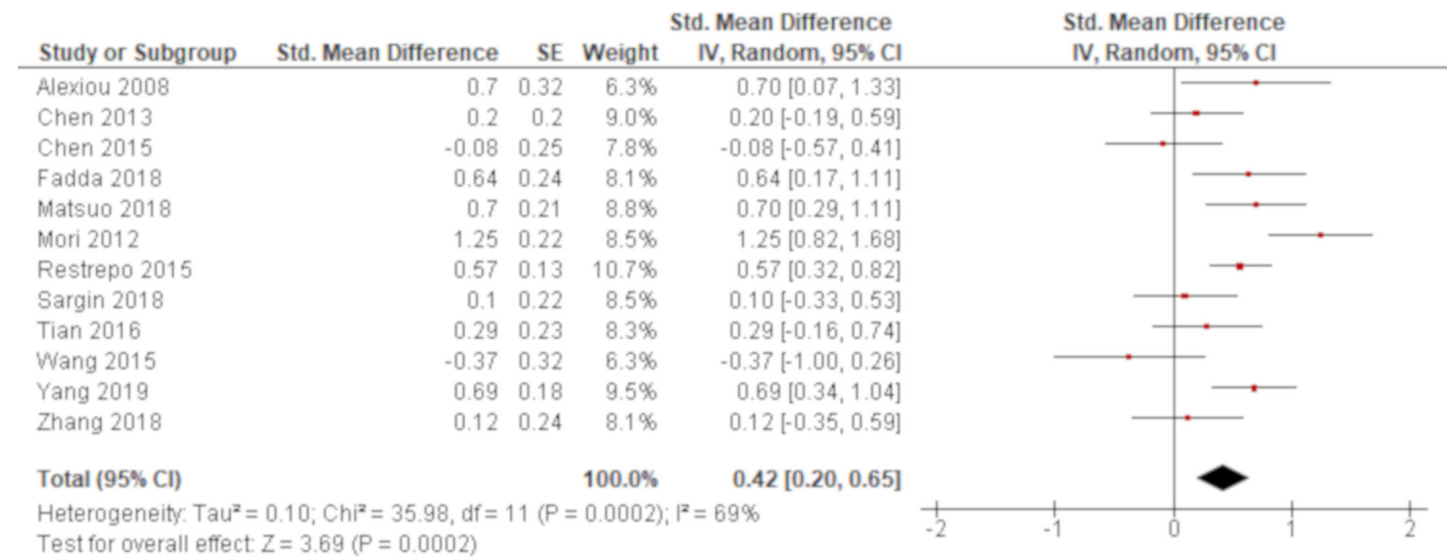

Figure 3 Forrest plot of the result of univariate analysis regarding the association of the tire of anti-cyclic citrullinated peptide (CCP) antibody with rheumatoid arthritis-associated interstitial lung disease (RA-ILD). The results of univariate analyses in 12 studies were pooled for meta-analysis. The titre of anti-CCP antibody was significantly higher for RA-ILD than RA without ILD with a standardised mean difference (SMD) of 0.42 (95\% Cl: 0.20 to $0.65, \mathrm{p}=0.0002 / 95 \%$ prediction interval: -0.33 to 1.17 ). There was considerable heterogeneity $\left(\chi^{2}=36.0, p=0.0002, I^{2}=69 \%\right)$. 
It is desirable and important to identify a high risk group of patients with RA who are likely to develop ILD because it is often progressive and worsens the prognosis of the disease. ${ }^{67}$ If the development of ILD can be predicted, it will help clinicians' decision-making and facilitate an efficient use of limited medical resources to change clinical course of the disease. Much effort has been made to identify clinical information such as serum biomarkers that can easily be obtained and help estimate the risk of ILD for patients with RA. ${ }^{68}$ Tests for ACPAs emerged as a tool to diagnose early RA with higher specificity than traditionally employed RF. ${ }^{69}$ They date back to the discovery of anti-perinuclear factor and anti-keratin antibody in the sera of patients with RA, which recognised the citrullinated protein filaggrin. ${ }^{70}$ Subsequently, CCP were synthesised to improve test performance ${ }^{71}$ and after further evolution currently the third generation of anti-CCP antibody test is commercially available. ${ }^{72}$ Anti-CCP antibody is both helpful to diagnose RA and also reported to be associated with extra-articular manifestations of the disease. ${ }^{73}$ The recent meta-analysis demonstrated an increased risk of RA-ILD as a result of serum anti-CCP antibody positivity. ${ }^{20}$ Although a number of specific citrullinated proteins were discovered such as fibrinogen ${ }^{74}$ and $\alpha$-enolase ${ }^{75}$ a diagnostic significance of specific autoantibodies directed against these autoantigens has yet to be established. $^{76}$

RA is classified as a systemic autoimmune disorder although the pathogenesis of the disease has been under dispute for many years. ${ }^{77}$ Recent research suggests that the breakdown of immunological tolerance initially occurs in the lungs under the influence of environmental stress such as exposure to cigarette smoke and genetic susceptibility. ${ }^{78}$ In short, smoking accelerates the activity of the enzyme peptidylarginine deiminase that catalyses the post-translational convert of arginine to citrulline, which eventually induces autoimmune reaction and leads to the formation of autoantibodies against citrullinated peptides under the interplay of both $\mathrm{T}$ and B lymphocytes. ${ }^{79} \mathrm{In}$ these processes, a number of cytokines are generated and may promote fibrotic changes of the lung. ${ }^{80}$ Smoking is related to the development of ILD, in particular, UIP, which is the most common type among RA-ILDs ${ }^{9}$ and contributes to the formation of ACPAs. Therefore, it is most likely that anti-CCP antibody is closely associated with the development of ILD for genetically susceptible subjects with smoking history and this relationship was confirmed in this report.

The current study is different from the previous systematic review ${ }^{20}$ in that it included a larger number of studies and subjects and thus the result is considered more reliable. It also demonstrated that the titre of anti-CCP antibody was higher for RA-ILD than RA without ILD. This finding is meaningful because anti-CCP antibody may be positive in the majority of patients with RA regardless of the presence of ILD. Indeed, the proportion of positivity of anti-CCP antibody for RA without ILD in this review ranged from $49.1 \%$ to $95.8 \%$ with the median value of 
$71.0 \%$. When the group of RA without ILD is positive for anti-CCP antibody with high frequency, the benefit of the autoantibody test for screening patients with RA at a higher risk of developing ILD will be limited. Conversely, the finding of titres may be more informative because it can also be employed to patients with RA without ILD who are tested positive for the autoantibody. Therefore, titres of anti-CCP antibody may be more useful than just its presence to estimate the risk of developing ILD. However, the interpretation of this finding also needs a caution because it was derived from a comparison between RA-ILD and RA without ILD and thus does not indicate any cut-off point that defines a high or low titre of the autoantibody. As a result, in usual clinical practice, clinicians need to assess the implication of the titre of anti-CCP antibody in the context of a total evaluation. If the titre of the autoantibody is combined with clinical features such as age, gender and smoking history alongside with other biomarkers such as Krebs von den Lungen-6 (KL-6), creating composite scores, it would be more beneficial to identify a group with a higher risk of developing ILD. However, what makes the issue more complicated is the variability of measurements of anti-CCP antibody, which was produced by a number of manufacturers. The sensitivity and specificity vary depending on the tests and the titres are also different between assays. ${ }^{81}$ Although an SMD was employed in this review to enable the comparison of titres derived from different tests, the result may be difficult to be applied in clinical practice. Furthermore, anti-CCP antibody is reported to be closely associated with bronchiolar disease, which is also a common pulmonary complication associated with RA alongside with ILD. ${ }^{54}$ Although bronchiolar disease was excluded in this review, it is possible that the disease was missed by the researcher or not selectively reported. If this was the case, the precise association of anti-CCP antibody with RA-ILD would be compromised. Anti-CCP antibody may also be affected by a number of other potential confounders such as age, gender, smoking history, RA duration, diagnostic criteria for RA and ILD and the proportion of positivity of anti-CCP antibody, which were diverse between studies. Although none of these confounders were found to be significantly associated with the heterogeneity of the results, it may possibly have been influenced by other clinical factor such as previous treatment. Therefore, the findings of this review may not be directly applicable to usual clinical practice and clinicians should consider all of the factors that can affect the presence or titres of anti-CCP antibody and assess the risk of ILD for patients with RA on a case-by-case basis.

There are other methodological limitations or caveats that need to be kept in mind to appropriately interpret the findings of this study. First, this review specifically focused on anti-CCP antibody and excluded ACPAs that were not specified as anti-CCP antibody since it may have represented autoantibodies against different citrullinated peptides. However, ACPAs other than anti-CCP antibody are not usually used in clinical practice and many rheumatologic teams may use the term ACPA for anti-CCP antibody. Therefore, this narrow inclusion criterion may have excluded some studies with a large number of subjects that could have reinforced the strength of meta-analysis. Second, this review was only composed of cross-sectional and case-control studies and thus causality between anti-CCP antibody and RA-ILD cannot be deducted although it is aetiologically plausible. Third, selection bias of subjects in individual studies cannot be ruled out. Patients with RA-ILD at relatively advanced stage may have been included for the review. If this was the case, the findings may not be applicable to an early stage of the disease and become useless for screening purpose. Fourth, anti-CCP antibody may be most closely related to UIP among other types of ILD complicated with RA. However, the association between anti-CCP antibody and individual ILD patterns could not be elucidated in this review because most of the studies did not report them. Finally, no studies were deemed as low risk of bias given that most of them were retrospectively designed cross-sectional or case-control studies. Due to this study limitation, the level of evidence obtained from this review was all rated as low or very low although univariate results in relatively a large number of studies were combined to generate an average estimate. Therefore, more research with high quality using a prospective cohort design needs to be accumulated to make a definitive conclusion or solidify the findings of this review.

\section{CONCLUSION}

This systematic review and meta-analysis suggested that the presence of anti-CCP antibody was significantly associated with RA-ILD and the titre of the autoantibody was significantly higher for RA-ILD than RA without ILD. However, an applicability of these findings may be limited due to the heterogeneity of included studies.

Contributors HK planned the entire research project and analysed the data. He also summarised the result and wrote the manuscript. HK has full access to the data and takes responsibility for its integrity as well as the accuracy of the analysis. OMP contributed to the design of the research project and conducted the literature search and data extraction. He was also involved in revising the manuscript. All researchers provided thoughts and opinions to compile a draft paper and approved of the final version of the manuscript.

Funding The authors have not declared a specific grant for this research from any funding agency in the public, commercial or not-for-profit sectors.

Competing interests None declared.

Patient consent for publication Not required.

Ethics approval Neither ethics approval nor participant consent was required as this study was based solely on the summary results of previously published articles. Individual patient data were not obtained or accessed.

Provenance and peer review Not commissioned; externally peer reviewed.

Data availability statement Data are available upon reasonable request. The data set used and/or analysed for this review will be available from the corresponding author upon a reasonable request and may become open to the public through a digital repository (such as Dryad) after the final result is published in a journal.

Supplemental material This content has been supplied by the author(s). It has not been vetted by BMJ Publishing Group Limited (BMJ) and may not have been peer-reviewed. Any opinions or recommendations discussed are solely those 
of the author(s) and are not endorsed by BMJ. BMJ disclaims all liability and responsibility arising from any reliance placed on the content. Where the content includes any translated material, BMJ does not warrant the accuracy and reliability of the translations (including but not limited to local regulations, clinical guidelines, terminology, drug names and drug dosages), and is not responsible for any error and/or omissions arising from translation and adaptation or otherwise.

Open access This is an open access article distributed in accordance with the Creative Commons Attribution Non Commercial (CC BY-NC 4.0) license, which permits others to distribute, remix, adapt, build upon this work non-commercially, and license their derivative works on different terms, provided the original work is properly cited, appropriate credit is given, any changes made indicated, and the use is non-commercial. See: http://creativecommons.org/licenses/by-nc/4.0/.

\section{ORCID iD}

Hiroyuki Kamiya http://orcid.org/0000-0001-5623-1279

\section{REFERENCES}

1 Smolen JS, Aletaha D, Mclnnes IB. Rheumatoid arthritis. Lancet 2016;388:2023-38.

2 Turesson C. Extra-articular rheumatoid arthritis. Curr Opin Rheumatol 2013;25:360-6.

3 Shaw M, Collins BF, Ho LA, et al. Rheumatoid arthritis-associated lung disease. Eur Respir Rev 2015;24:1-16.

4 lqbal K, Kelly C. Treatment of rheumatoid arthritis-associated interstitial lung disease: a perspective review. Ther Adv Musculoskelet Dis 2015;7:247-67.

5 Hozumi H, Nakamura Y, Johkoh T, et al. Acute exacerbation in rheumatoid arthritis-associated interstitial lung disease: a retrospective case control study. BMJ Open 2013;3:e003132.

6 Nurmi HM, Purokivi MK, Kärkkäinen MS, et al. Variable course of disease of rheumatoid arthritis-associated usual interstitial pneumonia compared to other subtypes. BMC Pulm Med 2016;16:107

7 Turesson C, Jacobsson L, Bergström U. Extra-articular rheumatoid arthritis: prevalence and mortality. Rheumatology 1999;38:668-74.

8 Bongartz T, Nannini C, Medina-Velasquez YF, et al. Incidence and mortality of interstitial lung disease in rheumatoid arthritis: a population-based study. Arthritis Rheum 2010;62:1583-91.

9 Tsuchiya Y, Takayanagi N, Sugiura H, et al. Lung diseases directly associated with rheumatoid arthritis and their relationship to outcome. Eur Respir J 2011;37:1411-7.

10 Solomon JJ, Ryu JH, Tazelaar HD, et al. Fibrosing interstitial pneumonia predicts survival in patients with rheumatoid arthritisassociated interstitial lung disease (RA-ILD). Respir Med 2013;107:1247-52.

11 Paulin F, Babini A, Mamani M, et al. Practical approach to the evaluation and management of rheumatoid arthritis-interstitial lung disease based on its proven and hypothetical mechanisms. Rev Invest Clin 2017;69:235-42.

12 Gabbay E, Tarala R, Will R, et al. Interstitial lung disease in recent onset rheumatoid arthritis. Am J Respir Crit Care Med 1997;156:528-35.

13 Gochuico BR, Avila NA, Chow CK, et al. Progressive preclinical interstitial lung disease in rheumatoid arthritis. Arch Intern Med 2008;168:159-66.

14 Habib HM, Eisa AA, Arafat WR, et al. Pulmonary involvement in early rheumatoid arthritis patients. Clin Rheumatol 2011;30:217-21.

15 Zhang Y, Li H, Wu N, et al. Retrospective study of the clinical characteristics and risk factors of rheumatoid arthritis-associated interstitial lung disease. Clin Rheumatol 2017;36:817-23.

16 Aletaha D, Neogi T, Silman AJ. Rheumatoid arthritis classification criteria: an American College of Rheumatology/European League Against Rheumatism collaborative initiative. Arthritis Rheum 2010;2010:2569-81.

17 Aubart F, Crestani B, Nicaise-Roland P, et al. High levels of anticyclic citrullinated peptide autoantibodies are associated with co-occurrence of pulmonary diseases with rheumatoid arthritis. $J$ Rheumatol 2011;38:979-82.

18 Inui N, Enomoto N, Suda T, et al. Anti-cyclic citrullinated peptide antibodies in lung diseases associated with rheumatoid arthritis. Clin Biochem 2008;41:1074-7.

19 Jearn L-H, Kim T-Y. Level of anticitrullinated peptide/protein antibody is not associated with lung diseases in rheumatoid arthritis. $J$ Rheumatol 2012;39:1493-4.

20 Zhu J, Zhou Y, Chen X, et al. A metaanalysis of the increased risk of rheumatoid arthritis-related pulmonary disease as a result of serum anticitrullinated protein antibody positivity. J Rheumatol 2014;41:1282-9.

21 Moher D, Liberati A, Tetzlaff J, et al. Preferred reporting items for systematic reviews and meta-analyses: the PRISMA statement. Ann Intern Med 2009;151:264-9.

22 Stroup DF, Berlin JA, Morton SC, et al. Meta-analysis of observational studies in epidemiology: a proposal for reporting. Meta-analysis of observational studies in epidemiology (MOOSE) group. JAMA 2000;283:2008-12.

23 Arnett FC, Edworthy SM, Bloch DA, et al. The American Rheumatism Association 1987 revised criteria for the classification of rheumatoid arthritis. Arthritis Rheum 1988;31:315-24.

24 American Thoracic Society. American Thoracic Society/European Respiratory Society international multidisciplinary consensus classification of the idiopathic interstitial pneumonias. Am J Respir Crit Care Med 2002;165:277-304.

25 Travis WD, Costabel U, Hansell DM, et al. An official American Thoracic Society/European Respiratory Society statement: update of the international multidisciplinary classification of the idiopathic interstitial pneumonias. Am J Respir Crit Care Med 2013;188:733-48.

26 Suzuki K, Sawada T, Murakami A, et al. High diagnostic performance of ELISA detection of antibodies to citrullinated antigens in rheumatoid arthritis. Scand J Rheumatol 2003;32:197-204.

27 Lopez-Olivo MA, Siddhanamatha HR, Shea B, et al. Methotrexate for treating rheumatoid arthritis. Cochrane Database Syst Rev 2014:CD000957.

28 Haddaway NR, Collins AM, Coughlin D, et al. The role of google scholar in evidence reviews and its applicability to grey literature searching. PLoS One 2015;10:e0138237.

29 Kamiya H, Panlaqui OM. Prognostic significance of autoantibodies for idiopathic pulmonary fibrosis: protocol for a systematic review. BMJ Open 2018;8:e020862.

30 Hayden JA, Côté P, Bombardier C. Evaluation of the quality of prognosis studies in systematic reviews. Ann Intern Med 2006;144:427-37.

31 Hedges LV. Distribution theory for Glass's estimator of effect size and related estimators. J Educ Behav Stat 1981;6:107-28.

32 Wan X, Wang W, Liu J, et al. Estimating the sample mean and standard deviation from the sample size, median, range and/or interquartile range. BMC Med Res Methodol 2014;14:135.

33 DerSimonian R, Laird N. Meta-analysis in clinical trials. Control Clin Trials 1986;7:177-88.

34 Higgins JPT, Green S. Cochrane Handbook for systematic reviews of interventions version 5.1.0. The Cochrane collaboration 2011

35 Riley RD, Higgins JPT, Deeks JJ. Interpretation of random effects meta-analyses. BMJ 2011;342:d549.

36 Egger M, Davey Smith G, Schneider M, et al. Bias in meta-analysis detected by a simple, graphical test. BMJ 1997;315:629-34.

37 Huguet A, Hayden JA, Stinson J, et al. Judging the quality of evidence in reviews of prognostic factor research: adapting the grade framework. Syst Rev 2013;2:71.

38 Alunno A, Bistoni O, Pratesi F, et al. Anti-citrullinated alpha enolase antibodies, interstitial lung disease and bone erosion in rheumatoid arthritis. Rheumatology 2018;57:850-5.

39 England BR, Duryee MJ, Roul P, et al. Malondialdehydeacetaldehyde adducts and antibody responses in rheumatoid arthritis-associated interstitial lung disease. Arthritis Rheumatol 2019;71:1483-93.

40 Giles JT, Danoff SK, Sokolove J, et al. Association of fine specificity and repertoire expansion of anticitrullinated peptide antibodies with rheumatoid arthritis associated interstitial lung disease. Ann Rheum Dis 2014;73:1487-94.

41 Chen J, Shi Y, Wang X, et al. Asymptomatic preclinical rheumatoid arthritis-associated interstitial lung disease. Clin Dev Immunol 2013;2013:1-5

42 Chen J, Doyle TJ, Liu Y, et al. Biomarkers of rheumatoid arthritis-associated interstitial lung disease. Arthritis Rheumatol 2015;67:28-38.

43 Doyle TJ, Patel AS, Hatabu H, et al. Detection of rheumatoid arthritisinterstitial lung disease is enhanced by serum biomarkers. Am J Respir Crit Care Med 2015;191:1403-12.

44 Abdel-Mageed SA-H, Foda EE, Abdel-Azeez EM. Increased risk of rheumatoid arthritis-related pulmonary disease as a results of serum anticitrullinated protein antibody positivity. Egypt J Hosp Med 2019;76:3572-80.

45 Akiyama M, Kaneko Y, Yamaoka K, et al. Association of disease activity with acute exacerbation of interstitial lung disease during tocilizumab treatment in patients with rheumatoid arthritis: a retrospective, case-control study. Rheumatol Int 2016;36:881-9.

46 Alexiou I, Germenis A, Koutroumpas A, et al. Anti-cyclic citrullinated peptide-2 (CCP2) autoantibodies and extra-articular manifestations 
in Greek patients with rheumatoid arthritis. Clin Rheumatol 2008;27:511-3.

47 Correia CS, Briones MR, Guo R, et al. Elevated anti-cyclic citrullinated peptide antibody titer is associated with increased risk for interstitial lung disease. Clin Rheumatol 2019;38:1201-6.

48 Fadda S, Khairy N, Fayed $\mathrm{H}$, et al. Interstitial lung disease in Egyptian patients with rheumatoid arthritis: frequency, pattern and correlation with clinical manifestations and anti-citrullinated peptide antibodies level. The Egyptian Rheumatologist 2018;40:155-60.

49 Furukawa $\mathrm{H}$, Oka S, Shimada K, et al. Association of human leukocyte antigen with interstitial lung disease in rheumatoid arthritis: a protective role for shared epitope. PLoS One 2012;7:e33133.

50 Kakutani T, Hashimoto A, Tominaga A, et al. Related factors, increased mortality and causes of death in patients with rheumatoid arthritis-associated interstitial lung disease. Mod Rheumatol 2020;30:458-64.

51 Kelly CA, Saravanan V, Nisar M, et al. Rheumatoid arthritis-related interstitial lung disease: associations, prognostic factors and physiological and radiological characteristics--a large multicentre UK study. Rheumatology 2014;53:1676-82.

52 Liu Y, Liu C, Li L, et al. High levels of antibodies to citrullinated $\alpha$-enolase peptide-1 (CEP-1) identify erosions and interstitial lung disease (ILD) in a Chinese rheumatoid arthritis cohort. Clin Immunol 2019;200:10-15.

53 Matsuo T, Hashimoto M, Ito I, et al. Interleukin-18 is associated with the presence of interstitial lung disease in rheumatoid arthritis: a cross-sectional study. Scand J Rheumatol 2019;48:87-94.

54 Mori S, Koga Y, Sugimoto M. Different risk factors between interstitial lung disease and airway disease in rheumatoid arthritis. Respir Med 2012;106:1591-9.

55 Ortancıl Ö, Bulmus N, Özdolap S. Anti-Cyclic citrullinated peptide antibodies in rheumatoid arthritis and their relationship with extraarticular manifestations. Turk J Rheumatol 2011;26:193-8.

56 Park WH, Kim SS, Shim SC, et al. Visual assessment of chest computed tomography findings in anti-cyclic citrullinated peptide antibody positive rheumatoid arthritis: is it associated with airway abnormalities? Lung 2016;194:97-105.

57 Paulin F, Doyle TJ, Mercado JF, et al. Development of a risk indicator score for the identification of interstitial lung disease in patients with rheumatoid arthritis. Reumatol Clin 2019;: :30111-1. S1699-258X.

58 Restrepo JF, del Rincón I, Battafarano DF, et al. Clinical and laboratory factors associated with interstitial lung disease in rheumatoid arthritis. Clin Rheumatol 2015;34:1529-36.

59 Rocha-Muñoz AD, Ponce-Guarneros M, Gamez-Nava Jl, et al. Anti-cyclic citrullinated peptide antibodies and severity of interstitial lung disease in women with rheumatoid arthritis. $J$ Immunol Res 2015;2015:1-10.

60 Sargin G, Köse R, Şentürk T. Tumor-associated antigens in rheumatoid arthritis interstitial lung disease or malignancy? Arch Rheumatol 2018:33:431-7.

61 Sulaiman FN, Wong KK, Ahmad WAW, et al. Anti-cyclic citrullinated peptide antibody is highly associated with rheumatoid factor and radiological defects in rheumatoid arthritis patients. Medicine 2019;98:e14945.

62 Tian F, Li J, Tuo H. The anti-mutated citrullinated vimentin antibody as a potential predictor for rheumatoid arthritis associated interstitial lung diseases. Int J Clin Exp Med 2016;9:6813-8.

63 Wang T, Zheng X-J, Liang B-M, et al. Clinical features of rheumatoid arthritis-associated interstitial lung disease. Sci Rep 2015;5:14897.
64 Yang JA, Lee JS, Park JK, et al. Clinical characteristics associated with occurrence and poor prognosis of interstitial lung disease in rheumatoid arthritis. Korean J Intern Med 2019;34:434-41.

65 Yin Y, Liang D, Zhao L, et al. Anti-cyclic citrullinated peptide antibody is associated with interstitial lung disease in patients with rheumatoid arthritis. PLoS One 2014;9:e92449.

66 Zhang J, Li J, Yu X. Changes and clinical significance of serum tumor markers in patients with rheumatoid arthritis combined with interstitial lung disease. J Hainan Med Univ 2018;24:46-9.

67 Kim EJ, Elicker BM, Maldonado F, et al. Usual interstitial pneumonia in rheumatoid arthritis-associated interstitial lung disease. Eur Respir $J$ 2010;35:1322-8

68 Trouw LA, Mahler M. Closing the serological gap: promising novel biomarkers for the early diagnosis of rheumatoid arthritis. Autoimmun Rev 2012;12:318-22.

69 Taylor P, Gartemann J, Hsieh J, et al. A systematic review of serum biomarkers anti-cyclic citrullinated peptide and rheumatoid factor as tests for rheumatoid arthritis. Autoimmune Dis 2011;2011:815038

70 Girbal-Neuhauser E, Durieux JJ, Arnaud M, et al. The epitopes targeted by the rheumatoid arthritis-associated antifilaggrin autoantibodies are posttranslationally generated on various sites of (pro)filaggrin by deimination of arginine residues. $J$ Immunol 1999;162:585-94.

71 Schellekens GA, Visser $\mathrm{H}$, de Jong BA, et al. The diagnostic properties of rheumatoid arthritis antibodies recognizing a cyclic citrullinated peptide. Arthritis Rheum 2000;43:155-63.

72 Swart A, Burlingame RW, Gürtler I, et al. Third generation anticitrullinated peptide antibody assay is a sensitive marker in rheumatoid factor negative rheumatoid arthritis. Clin Chim Acta 2012;414:266-72.

73 Turesson C, Jacobsson LTH, Sturfelt G, et al. Rheumatoid factor and antibodies to cyclic citrullinated peptides are associated with severe extra-articular manifestations in rheumatoid arthritis. Ann Rheum Dis 2007:66:59-64.

74 Sebbag M, Moinard N, Auger I, et al. Epitopes of human fibrin recognized by the rheumatoid arthritis-specific autoantibodies to citrullinated proteins. Eur J Immunol 2006;36:2250-63.

75 Mahdi H, Fisher BA, Källberg H, et al. Specific interaction between genotype, smoking and autoimmunity to citrullinated alpha-enolase in the etiology of rheumatoid arthritis. Nat Genet 2009;41:1319-24.

76 Boman A, Brink M, Lundquist A, et al. Antibodies against citrullinated peptides are associated with clinical and radiological outcomes in patients with early rheumatoid arthritis: a prospective longitudinal inception cohort study. RMD Open 2019;5:e000946.

77 Scott DL, Wolfe F, Huizinga TWJ. Rheumatoid arthritis. Lancet 2010;376:1094-108.

78 Perry E, Kelly C, Eggleton P, et al. The lung in ACPA-positive rheumatoid arthritis: an initiating site of injury? Rheumatology 2014;53:1940-50.

79 Cavagna L, Monti S, Grosso V, et al. The multifaceted aspects of interstitial lung disease in rheumatoid arthritis. Biomed Res Int 2013;2013:759760

80 Brito Y, Glassberg MK, Ascherman DP. Rheumatoid arthritisassociated interstitial lung disease: current concepts. Curr Rheumatol Rep 2017;19:79.

81 Van Hoovels L, Jacobs J, Vander Cruyssen B, et al. Performance characteristics of rheumatoid factor and anti-cyclic citrullinated peptide antibody assays may impact ACR/EULAR classification of rheumatoid arthritis. Ann Rheum Dis 2018;77:667-77. 